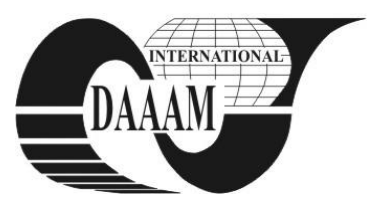

Annals of DAAAM for 2011 \& Proceedings of the 22nd International DAAAM Symposium, Volume 22, No. 1, ISSN 1726-9679 ISBN 978-3-901509-83-4, Editor B. Katalinic, Published by DAAAM International, Vienna, Austria, EU, 2011 Make Harmony between Technology and Nature, and Your Mind will Fly Free as a Bird Annals \& Proceedings of DAAAM International 2011

\title{
STRENGTH CALCULATIONS OF SLURRY DISPOSAL PIPELINE
}

\author{
PRISS, J[elena] \& KLEVTSOV, I[van]
}

\begin{abstract}
Estonia is the only country in the world that uses oil shale fired power plants to supply most of its electricity to domestic customers and can export power to neighboring countries. Estonian Energy Company is planning to develop production of higher quality liquid fuels from oil shale. It is suposed that these plans will lead to the design of a new slurry disposal pipeline. This paper presents an overview of strength calculations of slurry disposal pipeline based on the usage Rampa program.

Key words: oil shale, slurry disposal pipeline, strength calculations, Rampa program
\end{abstract}

\section{INTRODUCTION}

This paper is a part of ongoing $\mathrm{PhD}$ thesis "Piping optimization on the basis of strength condition analysis". After an overview of the theoretical issues the paper presents an overview of the results of slurry pipeline strength calculations performed by using Rampa program.

\section{OIL SHALE ASH AND ASH REMOVAL}

Oil shale as an energy-producing raw material is widely distributed around the world. The oil shale resources in Estonia are extensive and estimated to be more than 7 billions tons that allows to produce more than 900 million tons of shale oil.

Estonian oil shale belongs to the low-grade fuel group (Ots, 2004) and has the following proximate characteristics: low moisture content (11-13\%), high ash content (45-47\%) and high content of mineral carbon dioxide.

Ash, the solid residue formed during fuel combustion, is an important component. The amount of ash and especially its physical and chemical properties determine the design of the steam boiler, the processes in the gas ducts, the operating mode, the construction of the ash handling system, the type of ash precipitators and the effects on the surrounding environment.

The ash is transported by hydro removal system with a big amount of water $\left(10-20 \mathrm{~m}^{3}\right.$ for a ton of ash) to the ash fields where the slaking process takes place.

Ash removal technique with small amount of water has recently been tested at the Balti Power Plant (Arro et al., 2007). In fact, it was only an experiment where ash removal by dense slurry technology, suggested by the Hungarian company EGI, was implemented. In this case the ratio of water and ash was $\sim 1: 1$. The result of that test allowed to understand what happens when the amount of water used in ash removal system is decreased. Due to the small amount of water the flow of ash slurry across the ash field gets worse. In cases of small amounts of water or dry ash handling system it is better to use other methods (distribution piping allowing more uniform spreading of slurry, with the help of bulldozers, etc.)

\section{DEVELOPMENT OF ESTONIAN OIL PLANT}

Estonian Energy Company is planning to develop a production of higher quality liquid fuels from oil shale. It is suposed that these plans will lead to the design of a new ash disposal pipeline.
The preparations for the building of the new oil plant was started in 2009. The new plant will consume 2.26 million tonnes of oil shale per year and will produce 290,000 tonnes of shale oil, 75 million $\mathrm{m}^{3}$ of high calorific retort gas and 280 GWh of electricity.

The new oil plant will use a new, more reliable and higher unit capacity Enefit technology with much lower environmental impact, which has been developed jointly by Eesti Energia and the international engineering company Outotec ( $* * * 2011)$.

With the building of the new oil plant, Eesti Energia will take a significant step towards creating an industry producing high-quality liquid fuels in Estonia.

By 2016 Eesti Energia is planning to develop a production complex for producing higher quality liquid fuels from oil shale than the shale oil produced today, fuels which will meet all the legal requirements for use as motor fuel.

\section{CALCULATION PROGRAM}

The detailed description of Rampa program and comparison with other similar programs was presented in (Priss J. \& Klevtsov I., 2011) and (Popov A. et al., 2007).

Rampa carries out verifying calculation of strength in which, besides the internal pressure, it takes into account the effect on the pipeline of additional operational loads from the following factors:

- Weight of the tube, the transported fluid, heat-insulation and the fittings of pipeline system;

- Thermal expansions (self-compensation) of the pipeline;

- Thermal expansions and other deformations in structures of the attached equipment and supporting system;

- Possible residual curvature of the pipeline as a result of accumulation of plastic creep deformations, so-called "selfextensions".

At verifying calculation of durability of the pipeline the program defines equivalent stresses for all its testing sections and typical details (arc and sector elbows, tees), compares to allowed stress and comes to the conclusion of performing of standard conditions. Besides strength estimation the program calculates design loads on the equipment and supporting constructions at verifying calculation of pipeline system where the special stage of calculation is carried out for spring suspension (assembly, simplifying system adjustment).

\section{PIPELINE CHARACTERISTICS}

- The length of slurry disposal pipeline is $2209 \mathrm{~m}$.

- Number of supports is 145( Fig.1)

- Transporting product is oil shale ash and water mix named slurry (Table.1)

\begin{tabular}{|l|l|}
\hline Composition & $1: 5$ \\
\hline Mass \% suspension & 16.67 \\
\hline Suspension density $\mathrm{g} / \mathrm{cm}^{3}$ & 1.102 \\
\hline
\end{tabular}

Tab. 1. Experimental results of slurry density measurement 
1) External diameter $D_{o}$ and a thickness of a wall $\varnothing 627.6 \mathrm{x}$ $8.8 \mathrm{~mm}$

2) Radius $R$ and the maximum ovality of elbows $-R=61.4$ $\mathrm{cm}, a_{\text {мax }}=4 \%$;

3) Linear weight of a pipe with product, $m=4.87 \mathrm{kgf} / \mathrm{cm}$

4) Operating temperature $t_{O}=50^{\circ} \mathrm{C}$, pressure $P_{O}=10.2 \mathrm{bar}$;

5) Installation temperature, $t_{I}=10^{\circ} \mathrm{C}$;

6) Hydraulic test temperature $t_{H T}=10^{\circ} \mathrm{C}$, pressure $P_{H T}=16$ bar;

7) Average coefficient of linear expansion $\beta=1.15 \cdot 10^{-5} 1 / K$;

8) Modulus of elasticity in operating condition $E_{o}=2.03 \cdot 10^{5}$ $\mathrm{MPa}$, in cold condition $E_{c}=2.1 \cdot 10^{5} \mathrm{MPa}$;

9) Allowed stress in operating and cold condition $\left[\sigma_{o}\right]=\left[\sigma_{c}\right]=$ $140 \mathrm{~N} / \mathrm{mm}^{2}$;

10) Allowed stress amplitude for straight sections $\left[\sigma_{a}\right]_{s}=370$ $\mathrm{N} / \mathrm{mm}^{2}$ and for elbows of pipelines $\left[\sigma_{a}\right]_{e}=590 \mathrm{~N} / \mathrm{mm}^{2}$ for 1000 start-up;

11) Coefficient of relaxation of a material at operating temperature, $\chi_{o}=1$.

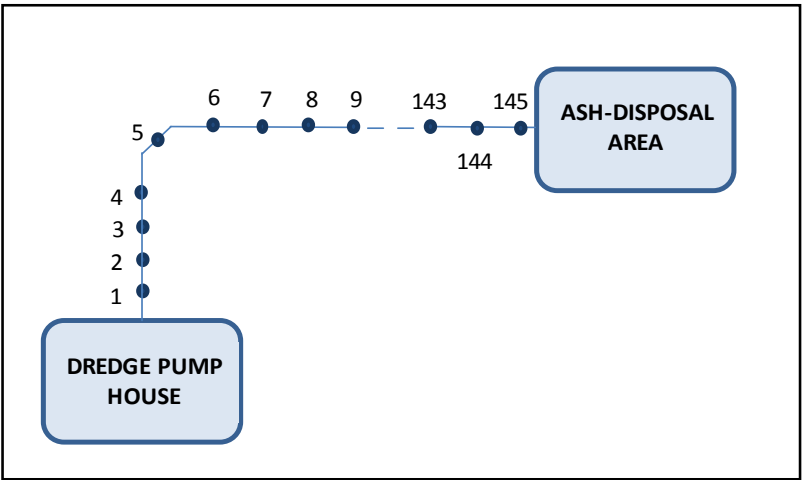

Fig. 1. Slurry disposal pipeline configuration scheme

\section{Pipeline calculation algorithm}

Two opportunities of pipeline design are taken into consideration:

a) The pipeline with rigid supports in the distance $75-90 \mathrm{~m}$ with sliding supports in the intervals $\sim 15 \mathrm{~m}$ tacking into account the friction in sliding supports (with the index of friction equals to 0.3 or to zero);

b) The pipeline with sliding supports in entire tube length tacking into account the friction in sliding supports (with the index of friction equals to 0.3 or to zero).

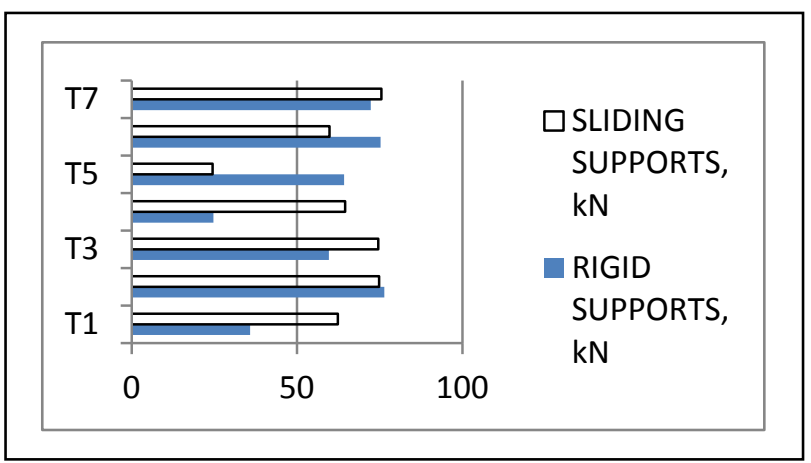

Fig. 2. Diagram of vertical loads on supports T1-T7

The calculation of pipeline for design a) with different value of index of friction was provided without taking into account the manometric effect of an oval elbow on a pipeline strength. As an example of vertical loads distribution in fig. 2 is presented the diagram of load vertical on supports T1-T7.

\section{CONCLUSION}

Strength calculations were carried out in four stages:

1. Estimation of static strength on joint effect of internal pressure, weight load, reactions of intermediate supports in operating conditions for the purpose of checking the possibility of achievement of its limiting condition at single loading (stage $1)$;

2. Estimation of long-term static strength on joint action of internal pressure, weight load, reactions of intermediate support in operating conditions, self-compensation of the temperature expansions, considering decrease in bearing ability of a material as a result of cumulation of creep plastic deformations (stage 2);

3. Estimation of cyclic fatigue strength on conditionally elastic stress from joint action of internal pressure, temperature expansions and efforts of resistance of the intermediate supports, arising at transition from cold to operating condition (stage 3);

4. Estimation of long-term static strength from weight load, efforts of intermediate supports and forces from pipelines to the equipment, and also residual compensatory loads and stresses of a self-extension at transition into cold condition, (stage 4).

\subsection{Pipeline with rigid supports, design a)}

The result of calculation of the pipeline with rigid and sliding supports taking or not taking into account the friction in sliding supports (index of friction $=0.3$ ) is positive and strength conditions are satisfied in all 4 stages. Axial loads in rigid supports are quite big, up to $1600 \mathrm{kN}$. Vertical loads depend on interval between supports. Total axial loads on supports depend on pipeline configuration that determine axial loads on particular rigid support from its left and right side. For example, the first rigid support $\mathrm{T} 8$ will get total axial loads $\mathrm{P}=1600$ $50=1550 \mathrm{kN}$. Such loads require very firm rigid support construction.

\subsection{Pipeline with sliding supports, design $b$ )}

The result of calculation of the pipeline with sliding supports (design $b$ ) is also positive in stages 1,2 and 4 but not satisfied in stage 3. In calculations with sliding supports it is supposed to analyse the reactions in supports for making the final conclusion.

\section{ACKNOWLEDGEMENTS}

I would like to thank "Doctoral school of energy and geotechnology II" and Internalisation Programme "DoRa" for financial support

\section{REFERENCES}

Arvo Ots, (2004) Oil shale fuel combustion, ISBN 9949-13710-7, ISBN 978-9949-13-710-1, Tallinn

Arro H.; Loosaar J.; Pihu T.\& Prikk A. (2007). Energy and Sustainability, WIT Press, ISSN 1743-3541, WIT Transactions on Ecology and Environment, Vol 105

Popov A., Vetoshkin V., Bukov V. (2007) The use of different software tools in designing high-temperature steam lines and carrying out their check calculations, Thermal Engineering, Vol. 54, No 10, ISSN PRINT: 0040-6015, pp. $836-841$

Priss J. \& Klevtsov I. (2011) The programs for strength calculation in pipelines, Proc. of 10th Int. Symp. "Topical problems in the field of electrical and power engineering", Pärnu.

*** (2011) https://www.energia.ee/en/oil/oilandgas/enefit280 